\title{
The modality of post-stimulus cueing of recall order in the memory span
}

\author{
JOHN MORTON, I Medical Research \\ Council, Applied Psychology Unit, 15 \\ Chaucer Road, Cambridge, England
}

Seven-digit sequences were recalled in either forward (F) or backward (B) order, with order of recall cued after the stimulus. The stimuli were presented acoustically, and the cue was visual. $F$ recall was significantly better than was $B$ recall in contrast to a study by Hinrichs (1968), who used a spoken postcue. It is concluded that the spoken postcue in that study was acting as a stimulus suffix, thus depressing the level of F recall.

Hintichs (1968) presented Ss with lists of digits to be recalled either in a forwards order (F) or in a backwards order (B). The order of recall was cued either before the stimulus list or after the list. He found that prestimulus cuing was superior to poststimulus cuing but reported no difference between $F$ and $B$ in the latter condition. Examination of his serial-position curves reveals that, in the poststimulus cuing condition, $F$ recall shows very little recency. As his method of presentation was auditory, this is surprising until one realizes that the cuing was also auditory. The cue word "forward" must then have been acting as a stimulus suffix (Crowder, 1967; Morton, 1968, 1969; Crowder \& Morton, 1969). The effect of a stimulus suffix is to depress the recall of the final two or three items in the case that recall is in the order of presentation. It is suggested then that the reduced recency effect found by Hinrichs in the poststimulus cued $F$ recall is not due to the nature of the cuing but to the modality of the cue.

\section{METHOD}

The Ss were 24 members of the APU S panel. Three $S s$ failed to follow instructions, and their data were not scored. The Ss were tested in a single group.

The Ss listened to a list of 54 sequences of seven digits. The digits were drawn from the set, 1-9, and were balanced for the serial-position occurrence of each digit in the two conditions.

The digits were presented through a tape recorder at the rate of $2 / \mathrm{sec}$, and the Ss recalled the sequences by writing each digit in a blank corresponding to its correct position. The order of recall required was cued by the E holding up a card on which was written the word "forwards" or the word "backwards." The two words occurred equally often in a random sequence. In $F$ recall, the digits were written from left to right; in B recall, they were written from right to left. A preliminary experiment had indicated that this was easier for the Ss than writing the B-recall digits from left to right, apparently because the resulting spacial position of the digits corresponded to their temporal order

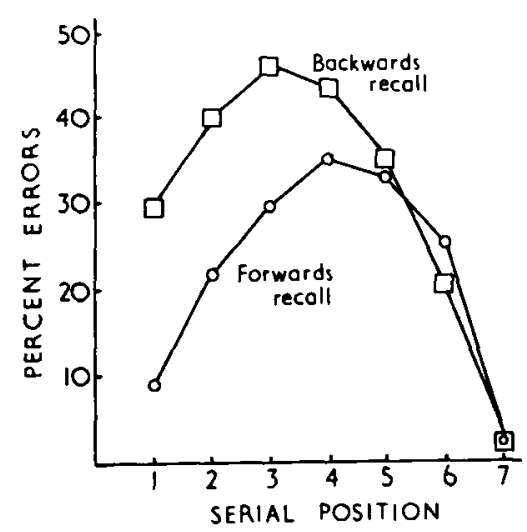

Fig. 1. The probability of an error as a function of presentation order, with order of recall cued after presentation. The stimuli were presented acoustically and the recall cue visually. no matter which method of recall was used. Ss had $12 \mathrm{sec}$ for recall and were required to guess rather than to leave blanks if they were uncertain. The group was given 18 practice lists, 9 under each condition, during which time any uncertainties were resolved, and any $S$ observed in an incorrect procedure was reinstructed. A response was scored correct only in the correct serial position.

$$
\text { RESULTS }
$$

The data are shown in Fig. 1. Twenty out of the 21 Ss performed better with $F$ recall than with $B$ recall $(T=1.5, n=21$, $\mathrm{p}<.001$, Wilcoxon), the mean number of digits recalled being $F=5.41, B=4.79$. In addition, it can be seen from the figure that there is no loss of recency in the $F$ recall, recall on the final item being identical in the two conditions.

There does appear to be some loss of primacy in the $F$ condition compared to normal serial recall. Performance on the initial item is invariably as good as that on the final item, with serial recall following acoustic presentation (Crowder \& Morton, 1969), whereas in the present experiment with $F$ recall, the last item was recalled significantly better $(T=2, n=12$, $p<.005$, Wilcoxon). Presumably, this is because Ss' rehearsal strategies are different under conditions where they do not know in advance the way in which they will have to recall the stimuli.

\section{DISCUSSION}

The prosent experiment confirms the suspicion that Hinrich's result was due to the modality of the cuing, and that poststimulus cuing of recall order does not of itself produce a reduction in the size of the recency effect. Unpublished experiments by Morton, Crowder, and Prussin (see Morton, 1969) have shown that a wide variety of speech events (including the word "recall") have an effect on the recall of the last few items of an acoustically presented list. To avoid confounding the results, poststimulus cues should either be presented visually or be nonspeech-like.

\section{REFERENCES}

CROWDER, R. G. Prefix effects in immediate memory. Canadian Journal of Psychology, $1967,21,450-461$.

CROWDER, R. G., \& MORTON, J. Precategorical acoustic storage (PAS). Perception \& Psychophysics, 1969, 5, 365-373.

HINRICHS, J. V. Prestimulus and poststimulus cueing of recall order in the memory span. Psychonomic Science, 1968, 12, 261-262.

MORTON, J. Repeated items and decay in memory. Psychonomic Science, 1968, 12, 219-220.

MORTON, J. Memory and word recognition: A functional model. In D. A. Norman (Ed.), Models for Human Memory. New York: Academic Press, 1969.

NOTE

1. The author is grateful to Mrs. S.M. Chambers for assistance with the data processing. 